\title{
Establishing a crude oil refinery in Koya
}

\author{
B. F. Ali \& S. J. Rashid \\ Petroleum Engineering Department, Koya University, \\ Kurdistan Region of Iraq
}

\begin{abstract}
The following paper proposes establishing a crude oil refinery near Taq Taq field in Koya city. This idea was developed due to the increasing demand on the transportation and heating fuel in Kurdistan generally and Koya city in particular. The major factor that encourages constructing this refinery is having enormous amounts of crude oil in the Taq Taq field, as well as constructing the new pipeline that connects Kurdistan oil with the Iraqi pipeline to Ceyhan fishkabur in Turkey. The study starts by introducing Taq Taq field and the importance of its geographic location, and then it provides a brief understanding of the refining process and its main steps. This paper also demonstrates the major products (fractions) of the petroleum refining process with a brief description of each fraction. Finally, it summarises the impact of establishing such a refinery on Koya city.

Keywords: Darbaro, Ceyhan, KRG, infrastructure, distillation.
\end{abstract}

\section{Introduction}

Our modern technological society relies very heavily on fossil fuels as an important source of energy. Crude oil as it comes from the ground is of little use and must undergo a series of refining processes which converts it into a variety of products - petrol for cars, fuel oil for heating, diesel fuels for heavy transport, bitumen for roads [1].

Petroleum refining is a unique and critical link in the petroleum supply chain, from the wellhead to the pump. The other links add value to petroleum mainly by moving and storing it (e.g., lifting crude oil to the surface; moving crude oil from oil fields to storage facilities and then to refineries; moving refined products from refinery to terminals and end-use locations, etc.). Refining adds value by converting crude oil (which in itself has little end-use value) into a range of 
refined products, including transportation fuels. The primary economic objective in refining is to maximize the value added in converting crude oil into finished products [5].

More than 660 refineries, in 116 countries, are currently in operation, producing more than 85 million barrels of refined products per day. Each refinery has a unique physical configuration, as well as unique operating characteristics and economics. A refinery's configuration and performance characteristics are determined primarily by the refinery's location, vintage, availability of funds for capital investment, available crude oils, product demand (from local and/or export markets), product quality requirements, environmental regulations and standards, and market specifications and requirements for refined products [5].

This article proposes establishing a crude oil refinery near Taq Taq field at Koya city. This idea was burn on 2003, when local authorities at Koya city proposed a certain location for building a crude oil refinery to the Ministry of Natural Resources at KRG and The Ministry of Oil- Iraq. The recommended location to establish such a refinery is the Darbaro area, near TLS (Tanker loading station) Taq Taq field, Koya/ Kurdistan Region of Iraq. The geographic location for this project represents a chain that connects the Taq Taq field, which contains tremendous amounts of crude oil with the International oil pipeline of Kirkuk - Ceyhan. The foundation is already exists and a budget had been settled for this project since 2003, but it was neglected in the following years because of lack of cooperation between the Iraqi government and the KRG.

\section{Koya and Taq Taq field}

The Taq Taq licence area is located $20 \mathrm{Km}$ southwest of the city of Koya, $60 \mathrm{~km}$ northeast of the Kirkuk oil field and the adjacent city of Kirkuk, $85 \mathrm{~km}$ southeast of the city of Erbil and $120 \mathrm{~km}$ northwest of the city of Sulaimaniyah. The gross area of the Taq Taq licence area is approximately 951 square $\mathrm{km}$ [2]. Figure 1 demonstrates Taq Taq field on the map, showing the main pipeline foundations and power plant.

According to the Genel Energy Company [2] there are currently 12 producing wells at Taq Taq, and the current production capacity of the field is 120,000 barrels per day with plans on track to increase this to 200,000 barrels per day in 2014.

There are four oil bearing zones that have been discovered in the Taq Taq field, one in the Oligocene Pilaspi formation and three in the Upper Cretaceous Shiranish, Kometan and Qamchuqa formations. The oil in Pilaspi formation is relatively heavy with an API gravity of 24 degrees, and the Cretaceous reservoirs contain a lighter, very low gas-to-oil ratio with an API gravity of 48 degrees.

The bottleneck to increasing production is the current truck transportation. Currently, crude oil used for exporting is trucked approximately $135 \mathrm{~km}$ to Khurmala or $255 \mathrm{~km}$ to Fishkabur, where it is metered and pumped into the Kirkuk-Ceyhan Pipeline. Crude oil allocated to the local sales market is picked up by trucks at the Taq Taq field. 
The KRG has in place pipeline infrastructure plans for the Kurdistan Region to facilitate the export of its crude oil production through the construction of a new pipeline to the Turkish border. The first phase directly connects Taq Taq to the Erbil refinery and the existing Kirkuk Ceyhan export infrastructure and is complete. The second phase, linking oil fields in the Kurdistan Region from Khurmala directly to Fishkabur on the Turkish border, is under construction and is expected to begin operating in the fourth quarter of 2013 [2].

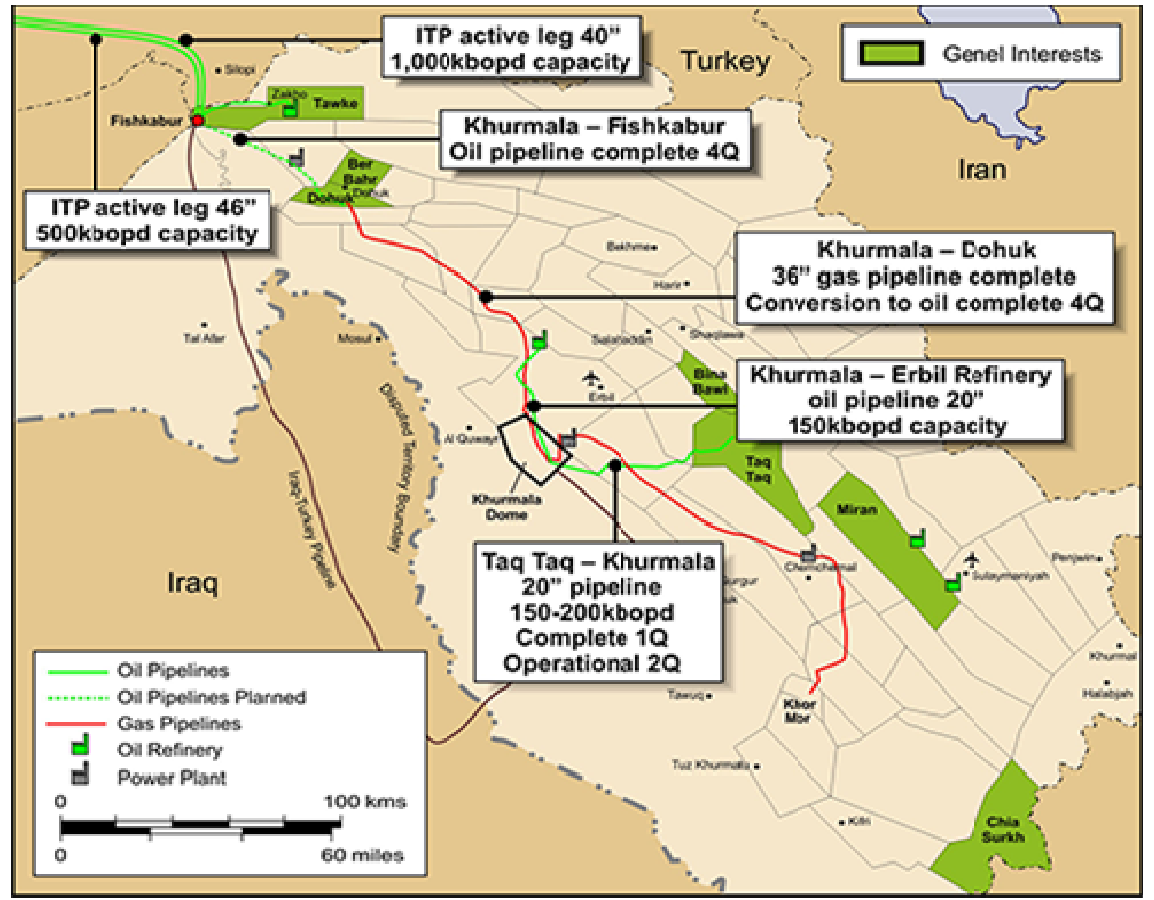

Figure 1: $\quad$ The map of Taq Taq field [2].

\section{Refining process}

The refining process depends on the chemical processes of distillation (separating liquids by their different boiling points) and catalysis (which speeds up reaction rates), and uses the principles of chemical equilibrium. Chemical equilibrium exists when the reactants in a reaction are producing products, but those products are being recombined again into reactants. By altering the reaction conditions the amount of either products or reactants can be increased [1].

Refining is carried out in three main steps.

\section{Step 1 - Separation}

The oil is separated into its constituents by distillation, and some of these components (such as the refinery gas) are further separated with chemical 
reactions and by using solvents which dissolve one component of a mixture significantly better than another.

\section{Step 2 - Conversion}

The various hydrocarbons produced are then chemically altered to make them more suitable for their intended purpose. For example, naphthas are "reformed" from paraffin and naphthene into aromatics. These reactions often use catalysis, and so sulfur is removed from the hydrocarbons before they are reacted, as it would 'poison' the catalysts used. The chemical equilibrium is also manipulated to ensure a maximum yield of the desired product.

\section{Step 3 - Purification}

The hydrogen sulfide gas which was extracted from the refinery gas in Step 1 is converted to sulfur, which is sold in liquid form to fertiliser manufacturers. The plant at Marsden Point also manufactures its own hydrogen and purifies its own effluent water. This water purification, along with gas 'scrubbing' to remove undesirable compounds from the gases to be discharged into the atmosphere, ensures that the refinery has minimal environmental impact [1].

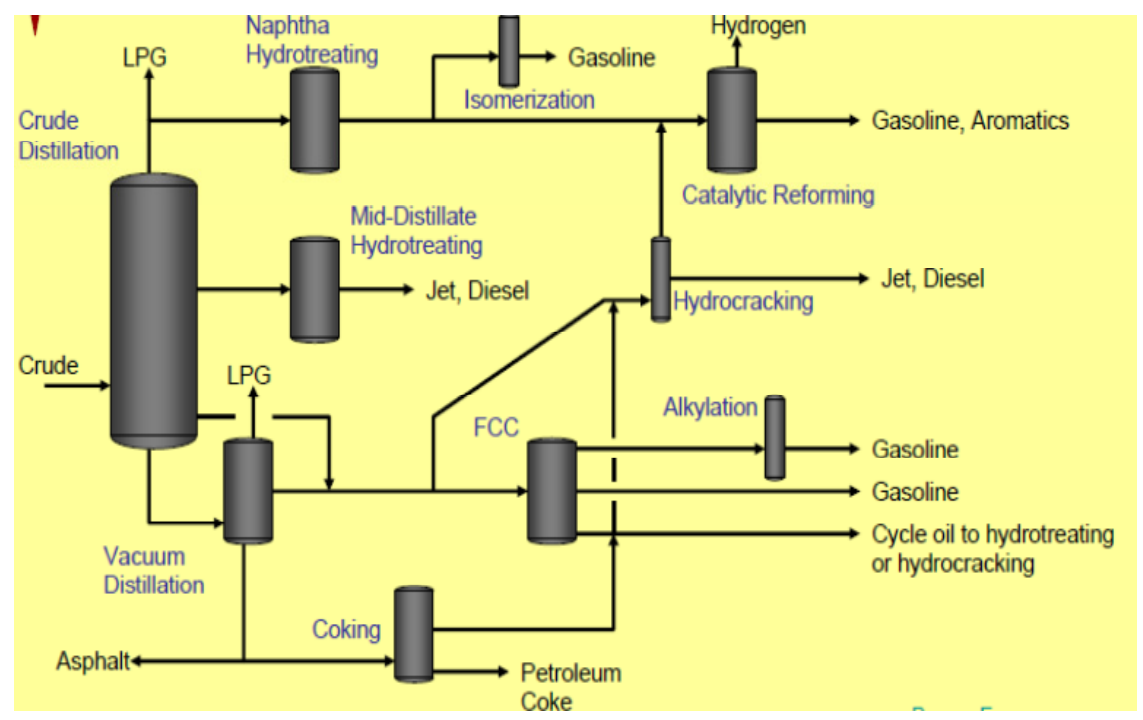

Figure 2: $\quad$ Generic process schematic [1].

\section{Fractions of crude oil}

Petroleum refineries are large, capital-intensive manufacturing facilities with extremely complex processing schemes. They convert crude oils and other input streams into dozens of refined (co-) products, including:

1- Petroleum gas: used for heating, cooking - small alkanes C1-C4 boiling point $\leq 40^{\circ} \mathrm{C}$. 
2- Naphtha: mix of alkanes C5-C9 - boiling point $60-100^{\circ} \mathrm{C}$.

3- Gasoline: used for motor fuel - liquid - mix of alkanes C5-C12 - boiling point $40-205^{\circ} \mathrm{C}$.

4- Kerosene: used for fuel jet engines and tractors - liquid - mix of alkanes C10-C18 - boiling point $175-325^{\circ} \mathrm{C}$.

5- Gas oil or diesel distillate: used for diesel fuel and heating oil - liquid alkanes C12 or above - boiling point $250-350^{\circ} \mathrm{C}$.

6- Lubricating oil: used for motor oil, grease - liquid - long chain C20-C50 alkanes, cycloalkanes aromatics- boiling point $300-370^{\circ} \mathrm{C}$.

7- Heavy gas or fuel oil: used for industrial fuel - liquid - long chain C20C70 alkanes, cycloalkanes aromatics - boiling point $370-600^{\circ} \mathrm{C}$.

8- Residuals: coke, asphalt, waxes. - solid - multiple ringed with C70 or above - boiling point $\geq 600^{\circ} \mathrm{C}$.

Of these, the transportation fuels have the highest value; fuel oils and asphalt the lowest value.

Many refined products, such as gasoline, are produced in multiple grades, to meet different specifications and standards (e.g., octane levels, sulphur content).

\section{The impact and benefits of this project on Koya}

1. Supplying petroleum products (gasoline, kerosene and gas oil) more flexibly to the city of Koya. Currently, these products are provided from the refineries in Erbil \& Kirkuk. The gasoline is supplied from both Kirkuk and Erbil refineries (72,000 L/day) per each, while the kerosene is supplied by Bazian refinery (50,000 L/day). Additionally, the gas oil is supplied by the Ministry of Natural Resources (MNR) and transported by trucks (108,000 L/day). Finally, the raw materials (crude oil) of all the above products are originally taken from Taq Taq field [4].

2. To reduce the trucks that transporting crude oil from Taq Taq field (TLS) to be refined in Erbil and Sulimaniah. Hence, this project is reducing the traffic congestions, car accidents \& maintaining the roads safety.

3. Saving the time by sending the crude oil by Pipeline to this refinery which is only few kilometres far from Taq Taq field.

4. Affects the economy of Koya city and provides more job opportunity to more people in Koya in this refinery and make Koya more developed.

5. An incredible development can be noticed on Koya city after building this project, as it is the case of the other cities in Kurdistan that have refineries. By the end of this project Koya changed from importing city to exporting city.

\section{References}

[1] Wansbrough, H. (2011). Refining Crude Oil. Available at: http://nzic.org.nz/ChemProcesses/energy/7A.pdf (accessed 9 September 2013). 
[2] Genel Energy Company. Taq Taq PSC. Available at: http://www.genelenergy.com/operations/kurdistan-region-of-iraq/taq-taqpsc.aspx (accessed 1 October 2013).

[3] Ronald F. Colwell, P.E. (2009). Oil Refinery Processes: A Brief Overview. Process Engineering Associates, LLC.

[4] The Directorate of Oil and Natural Resources at Koya city.

[5] Math Pro Inc. A report prepared for The International Council on Clean Transportation (ICCT). An Introduction to Petroleum Refining and the Production of Ultra low Sulfur Gasoline and Diesel Fuel. October 24, 2011. Also available at: http://www.theicct.org/sites/default/files /publications/ICCT05_Refining_Tutorial_FINAL_R1.pdf 